\title{
Clinical-epidemiological study of toxocariasis in a pediatric population
}

\author{
Silvana D. P. Figueiredo, ${ }^{1}$ José A. A. C. Taddei, $^{2}$ Joaquim J. C. Menezes, $^{3}$ \\ Neil F. Novo, ${ }^{4}$ Elizabete 0 . M. Silva, ${ }^{5}$ Helena L. G. Cristóvão, ${ }^{6}$ Maria C. F. S. Cury $^{7}$
}

\begin{abstract}
Objective: The variety of toxocariasis clinic manifestations and its relationship with asthma motivated this study. The aim was to study T.canis seropositivity at a public pediatric service and its association with laboratory, epidemiological and clinical factors.

Methods: This study was cross-sectional and controlled. Two hundred and eight children, from 1 to 14 years old and treated at the University of Santo Amaro Pediatric Department's Immunology and Pneumology clinic between January 2000 and January 2001, underwent serology testing. Antibodies were detected by ELISA testing for the larval excretory-secretory antigen of $T$. canis. We used the chi-square test for T.canis seropositivity (titers $\geq 1: 320$ ) associations with: puppies at home, contact with soil, geophagia, onicophagia, mother's educational level, asthma, chronic cough, repetitive pneumonia, skin manifestations, rhinitis, hepatomegaly, splenomegaly, abdominal pain, anemia, eosinophilia, immunoglobulins, parasitosis and stunted growth. The Kruskal-Wallis variance analysis method was used for mean comparisons between seropositive and seronegative groups. Significance was set at $p \leq 0.05$.

Results: Seroprevalence was $54.8 \%$, with a mean age of 6.5 years while for seronegative children the mean age was 5.8 years, showing no significant difference. There was also no difference between sexes. Seropositivity was significantly associated with puppies at home, contact with soil, hepatomegaly, asthma, eosinophilia, increased serum immunoglobulin (Ig) E levels and stunted growth.

Conclusion: Seroprevalence was elevated in this study. T.canis infection must be considered in at-risk children, such as those with puppies at home, who have had contact with soil, who have hepatomegaly and/or asthma with eosinophilia and increased serum IgE.
\end{abstract}

J Pediatr (Rio J). 2005;81(2):126-32: Toxocariasis, asthma, child.

\section{Introduction}

Toxocariasis is caused by migration and persistence of larvae, especially of Toxocara canis ${ }^{1}$ in organs of intermediate (paratenic) hosts, such as man. The principal source of the disease are puppies, which accomplish the life cycle of

1. MSc. Professor, Universidade de Santo Amaro, São Paulo, SP, Brazil.

2. Full professor, Universidade Federal de São Paulo (UNIFESP). Professor, Universidade de Santo Amaro, São Paulo, SP, Brazil.

3. MSc. Professor, Universidade de Santo Amaro, São Paulo, SP, Brazil.

4. PhD. Professor, Universidade de Santo Amaro, São Paulo, SP.

5. Biomedical physician, Tropical Medicina Institute, Universidade de São Paulo (USP), São Paulo, SP, Brazil.

6. MSc. Professor, Universidade de Santo Amaro, São Paulo, SP, Brazil.

7. PhD. Director of the Medical School, Universidade de Santo Amaro, São Paulo, SP, Brazil.

Manuscript received Aug 09 2004, accepted for publication Dec 082004

Suggested citation: Figueiredo SD, Taddei JA, Menezes JJ, Novo NF, Silva EO, Cristóvão $\mathrm{HL}$, et al. Clinical-epidemiological study of toxocariasis in a pediatric population. J Pediatr (Rio J). 2005;81:126-32.
Toxocara canis by eliminating the eggs of adult worms in their feces and contaminating the soil. Children are more susceptible to this infection because they handle contaminated soil.

Three clinical forms of toxocariasis have been described: visceral larva migrans (VLM), ocular larva migrans (OLM), and occult or covert (subclinical) toxocariasis (CT).

The classical form of toxocariasis (VLM) was described by Beaver et al. ${ }^{2}$ in 1952 as a relatively benign disease, characterized by eosinophilia, pulmonary disorders and hepatomegaly, affecting especially children aged between 1 and 5 years old. OLM, described by Nichols ${ }^{3}$ in 1956, is the result of the larval migration to the eyes, which may cause chorioretinitis, uveitis, strabismus and even blindness. ${ }^{4}$ It usually occurs in children aged older than 4 years or in adults without any other clinical signs, with low antibody titers, but eosinophilia rarely occurs. 
Thirty years ago, in 1983,5 Bass \& Mehta found a third form of toxocariasis while studying asymptomatic children who were seropositive for T. canis, with or without eosinophilia, called covert toxocariasis. Taylor et al., in 1987,6 reported clinical forms with nonspecific symptoms of toxocariasis, eosinophil levels lower and much more frequent than those observed in VLM.

With improved diagnosis, several epidemiological studies have been carried out, showing a high prevalence in any age group, including adults. Also, researchers have shown growing interest in studying the association of toxocariasis with several clinical forms, including allergic disorders, especially asthma. Due to the controversial results reported in the literature, we decided to conduct this study in order to assess the seroprevalence $T$. canis in our setting, to compare the seroprevalence of $T$. canis in asthmatic and nonasthmatic patients and to establish associations between seropositivity and clinical, laboratory and epidemiological variables.

\section{Methods}

From January 2000 to January 2001, serological studies were carried out with 208 children aged from 1 to 14 years in the region of Capela do Socorro, outskirts of São Paulo, where $50.6 \%$ of the population receives up to three minimum wages (SEADE - State Data Analysis System). Among the children treated by the Unified Health System at the outpatient clinics of Pediatrics, Immunology and Pulmonology of Universidade de Santo Amaro (state of São Paulo), 106 were asthmatic and 102 were nonasthmatic.

We conducted a cross-sectional, contemporaneous, controlled, observational study using a static design methodology and incomplete selection.

The interview with parents or surrogates and the clinical examination were performed by the main author, and all laboratory tests were done on admission.

The serological tests were performed by the Institute of Tropical Medicine of Universidade de São Paulo, and the anti-Toxocara canis antibodies were detected by ELISA using Toxocara canis excretory-secretory antigens (TES). All the sera were previously absorbed with Ascaris suum ${ }^{7}$ antigens, and those with titers $\geq 1: 320$ were regarded as seropositive. Epidemiological, clinical and laboratory variables included: age (classified into three groups: from 12 to 35 months and 29 days, from 36 to 71 months and 29 days, and above 72 months), gender, presence of puppies at home, contact with soil, geophagy, onychophagy, low level of maternal education (up to the fourth grade), absence of sewage system, weight, height, presence of asthma defined as three or more episodes of reversible bronchospasm (2nd Brazilian Consensus on Asthma Management, 1998), chronic cough (for over 3 weeks), history of three or more episodes of pneumonia, abdominal pain, skin disorders consisting of atopic dermatitis (pruritus, erythema, maculopapular rashes, pityriasis alba, xerosis) or urticaria, allergic rhinitis, hepatomegaly and splenomegaly (the latter three were evaluated by physical examination), considering age, according to Bricks et al. ${ }^{8}$ and confirmed by ultrasound. The cells for complete blood analysis were counted under a microscope, and anemia was considered when $\mathrm{Hb}$ was below $11 \mathrm{~g} / 100 \mathrm{ml}$, while eosinophilia corresponded to levels above $400 / \mathrm{mm}^{3}$. Immunoglobulins IgA, IgG and IgM were analyzed by turbidimetry, and the values were considered normal according to age, following the classification of Naspitz et al. ${ }^{9}$ IgE concentration was measured by radioimmunoassay, where levels greater than $200 \mathrm{IU} / \mathrm{dl}$ were considered elevated. For the assessment of nutritional status, the National Center of Health Statistics (NCHS) data were used as reference, and the values were expressed as standard deviation (z score). A z score $<-1.5$ was used as the cutoff point for malnutrition. The chi-square test was used to establish an association between variables and positive serology for $T$. canis, and the Epi-Info program, version 6, was employed. The Kruskal-Wallis rank sum test was used for the differences between the mean ages of seropositive and seronegative groups. A $p \leq 0.05$ was regarded as statistically significant.

Information regarding patient variables was lost due to several reasons (e.g.: some exams could not be found and some patients were lost to follow-up). Therefore, the number of children whose data about the variables were available is not the same as the number of evaluated children. The following pieces of information were obtained: 196 about the presence of puppies at home, 200 about contact with soil, 199 about geophagy, 198 about onychophagy, 195 about maternal education, 208 about asthma, 202 about cough, 205 about recurrent pneumonia, 192 about skin disorders, 161 about rhinitis, 204 about hepatomegaly, 200 about splenomegaly, 197 about abdominal pain, 198 about anemia, 197 about eosinophilia, 157 about elevated IgE levels, 156 about elevated IgA levels, 157 about elevated IgM levels, 156 about elevated IgG levels, and 208 about the presence of other parasitic diseases. As to nutritional status, 208 patients were assessed for weight /age, 177 for height/age and 155 for weight/ height.

All those patients who were positive for $T$. canis were referred for ophthalmological examination and treated with thiabendazole in the dose of $50 \mathrm{mg} / \mathrm{kg} /$ day for 7 days.

The study protocol was approved by the Research and Ethics Committee of Universidade de Santo Amaro. Mothers or surrogates received detailed information about the procedures, objective of the study, diagnostic importance and about the appropriate treatment for seropositive children.

\section{Results}

Of the 208 patients analyzed, 114 showed titers $\geq 1: 320$, and a seropositivity of $54.8 \%$. Genders were equally distributed: $57(50 \%)$ of the seropositive patients were female and $48(51.1 \%)$ were male $\left(\chi^{2}=0.02\right.$ and $\left.p=0.87\right)$.

The mean age was 6.5 years $(S D \pm 3.4)$ for seropositive patients and 5.8 years $(S D \pm 3.2)$ for seronegative ones. Mean age differences were not statistically significant, according to the Kruskal-Wallis rank sum test $(p=0.19)$. 
Figure 1 shows the distribution of serologic results across the different age groups. The associations with epidemiological, clinical and laboratory variables are portrayed in Tables 1, 2, 3 and 4.

There was a positive association between seropositivity and the presence of puppies at home $(p=0.006)$, contact with soil $(p=0.00002)$, asthma $(p=0.05)$, especially in children older than 3 years $(p=0.01$, hepatomegaly $(p=0.003)$, eosinophilia $(p=0.01)$, elevated IgE levels $(p=0.0007)$ and malnutrition in relation to height for age (0.03).

The ophthalmologic examination of seropositive patients yielded normal results.

\section{Discussion}

Seropositivity for Toxocara canis was high in our study, with titers greater than or equal to $1: 320$ in $54.8 \%$ of the cases, as in other developing countries. In a study carried out with children aged from 6 months to 6 years in Santa Lúcia ${ }^{10}$ (in the Caribbean), which used the same serological method as our study, seroprevalence amounted to $86 \%$.

In Brazil, a population-based study carried out in five towns in the state of São Paulo, involving adults and children, revealed a seroprevalence of $3.6 \%$, with a dilution of $1: 160 .{ }^{11}$ In our study, seroprevalence was much higher and the dilution used was larger, but our patient population does not correspond to the general population, but to those children who sought medical care, most of them with health problems; in addition to the low socioeconomic and educational level in our region. In Resistencia, Argentina, 12 a $37.95 \%$ seroprevalence was found in 26 children aged from 1 to 14 years, using a dilution of $1: 100$. This study was somewhat similar to ours regarding sample size, age groups, and the fact that Resistencia is also an underdeveloped town with subtropical climate.
No significant difference was found in terms of age in the different age groups analyzed in our study, as observed in Resistencia. The mean age corresponded to 6.5 years, similar to the one found in a hospital of Vitória, state of Espírito Santo, in children of the same age. ${ }^{13}$

We observed a large rate of $T$. canis infection among school-aged children, with $40.6 \%$ of seropositive individuals. Alderete investigated seroprevalence in school-aged children in the region of Butantã, São Paulo ${ }^{14}$ and found a rate of $38.8 \%$, but the cutoff dilution used was $1: 160$, lower than the one used in this study $(1: 320)$. This result may be explained by the different socioeconomic status of the population in these regions (SEADE - State Data Analysis System). In poor regions, such as Trinidad, ${ }^{15}$ the seroprevalence among school-aged children was higher, $62.3 \%$, with a cutoff dilution of $1: 100$.

We found a significant association between seropositivity and presence of puppies in all revised studies, $12,16,17$ which was also found in our study. Marmor et al. ${ }^{18}$ assert that the presence of dogs at home is the major risk factor for toxocariasis.

The association between contact with earth or sand and positive serology was highly significant in our study. The same did not occur with geophagy and onychophagy. This fact may be attributed to our inability to address the issue so as to obtain accurate information from mothers, a difficulty that was also reported by Glickman et al. ${ }^{19}$ We know that children have the habit of placing their fingers in their mouths, which may facilitate contamination by $T$. canis eggs. However, there are some studies showing a significant association between seropositivity and pica, especially geophagy ${ }^{17,18}$ and onychophagy. ${ }^{14}$

In our sample, we did not find any association between maternal level of education and seropositivity, probably due to the fact that this population lives in the same environment and is subjected to the same infections. Another factor that

Table 1 - Distribution of serologic results for $T$. canis seropositivity according to epidemiologic variables

\begin{tabular}{|c|c|c|c|c|c|}
\hline & Serum (+) & Serum (-) & Total & $\chi^{2}$ calculated & $\mathbf{p}$ \\
\hline \multicolumn{6}{|c|}{ Puppies } \\
\hline yes & $89(83.2 \%)$ & $59(66.3 \%)$ & 196 & 7.49 & 0.006 \\
\hline no & $18(16.8 \%)$ & $30(33.7 \%)$ & & & \\
\hline \multicolumn{6}{|l|}{ Soil } \\
\hline yes & $90(81.8 \%)$ & $49(54.4 \%)$ & 200 & 17.50 & 0.00002 \\
\hline no & $20(18.2 \%)$ & $41(45.6 \%)$ & & & \\
\hline \multicolumn{6}{|c|}{ Geophagia } \\
\hline yes & $14(12.8 \%)$ & $9(10 \%)$ & 199 & 0.39 & 0.53 \\
\hline no & $95(87.2 \%)$ & $81(90 \%)$ & & & \\
\hline \multicolumn{6}{|c|}{ Onicophagia } \\
\hline yes & $51(46.8 \%)$ & $39(43.8 \%)$ & 198 & 0.17 & 0.67 \\
\hline no & $58(53.2 \%)$ & $50(56.2 \%)$ & & & \\
\hline \multicolumn{6}{|c|}{ Mother's educational level } \\
\hline yes & $49(45.4 \%)$ & $35(40.2 \%)$ & 195 & 0.54 & 0.47 \\
\hline no & $59(54.6 \%)$ & $52(59.8 \%)$ & & & \\
\hline
\end{tabular}


Table 2 - Distribution of serologic results for $T$. canis seropositivity according to clinical variables

\begin{tabular}{|c|c|c|c|c|c|}
\hline & Serum $(+)$ & Serum (-) & Total & $\chi^{2}$ & $\mathbf{p}$ \\
\hline \multicolumn{6}{|l|}{ Asthma } \\
\hline yes & $65(57 \%)$ & $41(44.1 \%)$ & 208 & 3.70 & 0.05 \\
\hline no & $49(43 \%)$ & $53(56.9 \%)$ & & & \\
\hline \multicolumn{6}{|c|}{ Asthma in children $<3$ years-old } \\
\hline yes & $16(66.7 \%)$ & $08(33.3 \%)$ & 51 & 3.84 & 0.78 \\
\hline no & $17(63 \%)$ & $10(37 \%)$ & & & \\
\hline \multicolumn{6}{|c|}{ Asthma in children $>3$ years-old } \\
\hline yes & $43(52 \%)$ & $39(48 \%)$ & 144 & 5.80 & 0.01 \\
\hline no & $20(32 \%)$ & $42(68 \%)$ & & & \\
\hline \multicolumn{6}{|l|}{ Cough } \\
\hline yes & $24(21.6 \%)$ & $25(27.5 \%)$ & 202 & 0.93 & 0.33 \\
\hline no & $87(78.4 \%)$ & $66(72.5 \%)$ & & & \\
\hline \multicolumn{6}{|c|}{ Pneumonia } \\
\hline yes & $16(14.2 \%)$ & $14(15.2 \%)$ & 205 & 0.05 & 0.83 \\
\hline no & $97(85.8 \%)$ & $78(84.8 \%)$ & & & \\
\hline \multicolumn{6}{|c|}{ Skin manifestations } \\
\hline yes & $14(13.1 \%)$ & $8(9.4 \%)$ & 192 & 0.63 & 0.42 \\
\hline no & $93(86.9 \%)$ & $77(90.6 \%)$ & & & \\
\hline \multicolumn{6}{|l|}{ Rhinitis } \\
\hline yes & $68(79.1 \%)$ & $63(84 \%)$ & 161 & 0.64 & 0.42 \\
\hline no & $18(20.9 \%)$ & $12(16 \%)$ & & & \\
\hline \multicolumn{6}{|c|}{ Hepatomegaly } \\
\hline yes & $15(13.4 \%)$ & $2(2.2 \%)$ & 204 & 8.32 & 0.003 \\
\hline no & $97(86.6 \%)$ & $90(97.8 \%)$ & & & \\
\hline \multicolumn{6}{|c|}{ Splenomegaly } \\
\hline yes & $1(0.9 \%)$ & $2(33.3 \%)$ & 200 & 0.58 & 0.48 \\
\hline no & $109(99.1 \%)$ & $88(97.8 \%)$ & & & \\
\hline \multicolumn{6}{|c|}{ Abdominal pain } \\
\hline yes & $46(43 \%)$ & $37(41.1 \%)$ & 197 & 0.07 & 0.79 \\
\hline no & $61(57 \%)$ & $53(58.9 \%)$ & & & \\
\hline
\end{tabular}

Table 3 - Distribution of the serologic result for T. canis seropositivity according to laboratory variables

\begin{tabular}{|c|c|c|c|c|c|}
\hline & Serum $(+)$ & Serum (-) & Total & $\chi^{2}$ & $\mathbf{p}$ \\
\hline \multicolumn{6}{|l|}{ Anemia } \\
\hline yes & $13(12.3 \%)$ & $6(6.5 \%)$ & 198 & 1.87 & 0.17 \\
\hline no & $93(87.7 \%)$ & $86(93.5 \%)$ & & & \\
\hline \multicolumn{6}{|c|}{ Eosinophilia } \\
\hline yes & $71(67.6 \%)$ & $46(50.0 \%)$ & 197 & 6.31 & 0.01 \\
\hline no & $34(32.4 \%)$ & $46(50.0 \%)$ & & & \\
\hline \multicolumn{6}{|c|}{ Elevated IgE } \\
\hline yes & $56(66.7 \%)$ & $29(39.7 \%)$ & 157 & 11.42 & 0.0007 \\
\hline no & $28(33.3 \%)$ & $44(60.3 \%)$ & & & \\
\hline \multicolumn{6}{|c|}{ Elevated IgA } \\
\hline yes & $4(4.7 \%)$ & $2(2.8 \%)$ & 156 & 0.37 & 0.54 \\
\hline no & $81(95.3 \%)$ & $69(97.1 \%)$ & & & \\
\hline \multicolumn{6}{|c|}{ Elevated IgM } \\
\hline yes & $9(10.6 \%)$ & $6(8.3 \%)$ & 157 & 0.23 & 0.63 \\
\hline no & $76(89.4 \%)$ & $66(91.7 \%)$ & & & \\
\hline \multicolumn{6}{|c|}{ Elevated IgG } \\
\hline yes & $39(45.3 \%)$ & $24(40.4 \%)$ & 156 & 1.96 & 0.16 \\
\hline no & $47(54.7 \%)$ & $46(65.7 \%)$ & & & \\
\hline \multicolumn{6}{|c|}{ Parasitic diseases } \\
\hline yes & $45(39.5 \%)$ & $43(45.7 \%)$ & 208 & 0.83 & 0.36 \\
\hline no & $69(60.5 \%)$ & $51(54.35 \%)$ & & & \\
\hline
\end{tabular}


Table 4 - Distribution of serologic results of $T$. canis according to malnutrition

\begin{tabular}{cccccc}
\hline & Serum (+) & Serum (-) & Total & $\chi^{\mathbf{2}}$ & $\mathbf{p}$ \\
\hline $\begin{array}{c}\text { W/A } \\
\text { yes } \\
\text { no }\end{array}$ & $8(7 \%)$ & $108(93 \%)$ & 208 & 0.03 & 0.85 \\
H/A & $106(93 \%)$ & $88(93.3 \%)$ & & & \\
$\quad$ yes & & & & & \\
no & $15(16 \%)$ & $5(6 \%)$ & 177 & 4.34 & 0.03 \\
$\begin{array}{c}\text { W/H } \\
\text { yes } \\
\text { no }\end{array}$ & $79(84 \%)$ & $78(94 \%)$ & & & \\
\hline
\end{tabular}

$W / A=$ wight/age $; H / A=$ height/age; $W / H=$ weight/height.

also interfered with this result was the stratification of level of education into two groups only (younger and older than four years of schooling), with little heterogeneity. Such facts could mask the effect of the maternal level of education. However, Worley et al. ${ }^{17}$ detected higher antibody titers in children whose parents had a low level of education.

Some studies showed a higher seroprevalence in boys than in girls. ${ }^{15,20}$ In our study, we did not observe any difference, probably because both genders had the same risk factors, as previously described by other authors. ${ }^{12,21,22}$

In our study, we found a statistically significant association between seropositivity and asthma, especially in children older than three years, when the diagnosis of asthma is more clearly defined. Before this age, asthma is frequently caused by viral infections. ${ }^{23}$ Nonetheless, we found seropositive cases among wheezing infants, as reported by some authors. 24

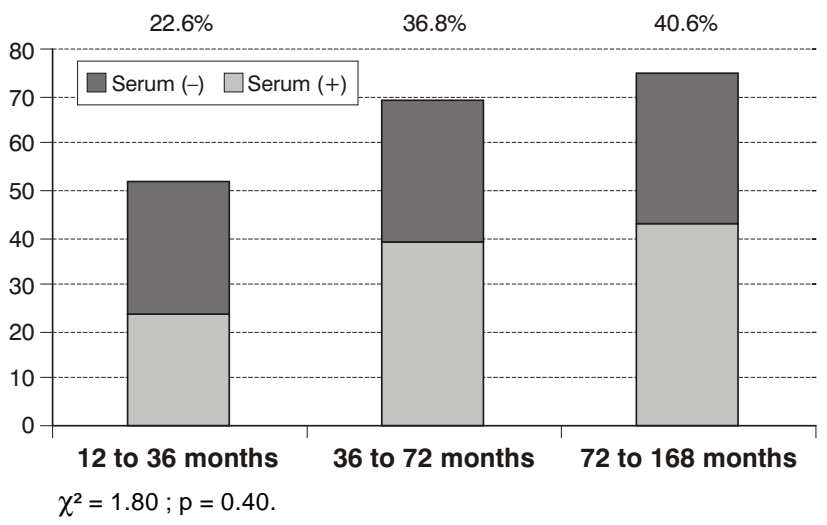

Figure 1 - Seroprevalence for Toxocara canis across the different age groups
The association between asthma and toxocariasis was described in some studies. Taylor et al. ${ }^{25}$ found higher antibody titers in asthmatic children than in the control group, but this was not observed by other authors. ${ }^{17}$ Desowitz et al. ${ }^{26}$ demonstrated that asthmatic children had a specific IgE antibody against $T$. canis in $28.8 \%$ of cases compared to $6.4 \%$ in nonasthmatic children. The authors attribute these discrepant results to genetic factors.

Some studies show this association in school-aged children and in preschoolers. A study conducted by Buijs et al. 27 in children aged 4 to 6 years revealed an association between seropositivity for $T$. canis and asthma and recurrent bronchitis and hospitalization for these reasons. Chan et al. ${ }^{28}$ evaluated children older than 5 years, among whom 66 were diagnosed with moderate to severe asthma, and 58 were nonasthmatic, and observed that asthmatic children showed a higher seropositivity for $T$. canis compared to nonasthmatic ones.

Some authors consider that toxocariasis can cause cough $^{6}$ and recurrent pneumonias. ${ }^{21}$ In our study, no association was observed between positive serology and cough and occurrence of three or more previous episodes of pneumonia. This is probably due to the fact that most of these patients have sought treatment at specialized outpatient clinics of allergy and pulmonology, and diseases found at these clinics (asthma, sinus diseases, sequelae arising from previous pneumonias) may cause the same problems.

Buijs et al. ${ }^{29}$ studied children with toxocariasis and found a significant association with allergic disorders, such as asthma and also with IgE specific to inhaled allergens. They reported that parasitic infection, including Toxocara infection, causes a nonspecific stimulation of quiescent allergic disorders in atopic children. Larval antigens encourage Th0 cells to develop Th2 cells, IL-4 (which stimulates IgE production by B lymphocytes) and IL-5 
(which stimulates the production and maturation of eosinophils). The ability of Toxocara larvae to survive in their hosts for months in a row stimulates Th2 cells and the consequent production of IgE for a long time. The authors suggest that only children who are predisposed to atopic disease show an association between Toxocara canis infection and allergic reactions. This explains the fact that we found a positive association between asthma and positive serology for $T$. canis in our sample.

Minvielle et al. ${ }^{30}$ compared individuals aged between 15 and 65 years and found a higher seropositivity (specific antiToxocara IgG and IgE) in asthmatic patients regarding other allergic symptoms, such as rhinitis, rhinosinusitis and dermatitis. They also observed an association between skin hypersensitivity to the $T$. canis excretory-secretory (TES) antigen and asthma. Admittedly, larval migration provokes host sensitivity to TES with an increase in specific IgE. This Ig binds to the membrane of bronchiolar and alveolar mast cells and releases mediators that lead to the inflammation of the bronchial mucosa and to the asthmatiform syndrome.

In our study, we did not find any association between toxocariasis and atopic dermatitis, as observed in some studies; 6,29 but this association was described in other studies. ${ }^{27}$ Nevertheless, in our patient population, there were two cases of chronic urticaria in toxocariasis patients, followed by hepatomegaly, eosinophilia, increased IgE levels, and one of them also showed splenomegaly, corresponding to the classic case of toxocariasis (VLM). These cases resolved after thiabendazole therapy. Other controlled studies should be carried out to confirm this association.

The lack of association of toxocariasis with allergic rhinitis in our study was also observed in a controlled study performed by Taylor et al. 6 , but this author, in a later study, 25 found predominance of nasal congestion in individuals with higher antibody titers, suggesting that this association depends on the serological level as well as hepatomegaly.

Hepatomegaly and splenomegaly are characteristic signs of the classic toxocariasis. It is important to highlight that, in all these cases, eosinophilia is intense, being used as a criterion for the investigation of toxocariasis. In the subclinical forms of toxocariasis, with less intense eosinophilia, the proportion of hepatomegaly and splenomegaly decreases in relation to the classic forms. This is what we observed in our study. Of the 112 patients with positive serology, 15 $(13.4 \%)$ had hepatomegaly (other etiologies were ruled out), and one of them also showed splenomegaly, corresponding to the classic forms of toxocariasis (VLM). The remaining cases ( $86.6 \%)$ correspond to the subclinical forms of toxocariasis or or CT.

Taylor et al. ${ }^{6}$ found the association of toxocariasis with hepatomegaly to be highly significant. However, this result was not found in other studies. ${ }^{17,19}$ In our study, there was no association between seropositivity and splenomegaly, probably due to the small number of cases.

We observed extremely significant associations between positive serology for $T$. canis with elevated IgE levels (above $200 \mathrm{IU} / \mathrm{dl}$ ) and eosinophilia (above $400 \mathrm{cells} / \mathrm{mm}^{3}$ ). These cutoff points are the same used by Glickman et al. ${ }^{16}$ These authors observed that patients with peripheral blood levels of eosinophils and IgE above these values had an $82 \%$ probability of having toxocariasis. Other studies also demonstrated these associations, 12,18 which suggests the allergic nature of $T$. canis infection. With regard to anemia and immunoglobulin (IgA, IgG and IgM) levels, although there were a larger number of cases among seropositive individuals, the association was not statistically significant. Nevertheless, this association was shown by some authors. 19,25

In terms of nutrition, there was an association between lower height for age (H/A) and seropositivity. This did not occur with weight for age (W/A) and weight for height $(\mathrm{W} / \mathrm{H})$. This result suggests the chronic nature of $T$. canis infection, which probably is associated with other morbidities (e.g.: asthma and chronic lung diseases), which also lead to impaired longitudinal growth. However, a controlled study carried out by Worley et al. ${ }^{17}$ did not show any significant difference between seropositive children and the control group in relation to the anthropometric indices.

The presence of other parasitic infections in seropositive patients showed no association, denoting high specificity of the serological method used.

In our sample, we did not find any association between seropositivity and abdominal pain, probably because a larger number of children had other parasitic diseases (42.3\% of the analyzed cases). The literature describes different results. Worley et al. ${ }^{17}$ studied preschoolers and did not find any association between abdominal pain and seropositivity for $T$. canis. However, Taylor et al. ${ }^{6}$ found a higher prevalence of abdominal pain in seropositive children, especially in those with higher antibody titers.

Our study showed that toxocariasis is very common among children in our setting. It affects both genders and occurs at any age, and its main risk factors are the presence of puppies at home and contact with earth or sand. Hepatomegaly and asthma should be regarded as a cause (especially in children aged older than 3 years) when eosinophilia is greater than 400 cells $/ \mathrm{mm}^{3}$ or IgE levels exceed $200 \mathrm{IU} / \mathrm{dl}$ in patients with positive epidemiology for T. canis.

It is important to raise the awareness of health professionals, public powers and educators to the fact that toxocariasis is a public health problem, so preventive measures, including canine population control, and diagnosis and treatment are necessary.

\section{References}

1. Cypess RH, Karol MH, Zidian JL, Glickman LT, Gitlin D. Larvaspecific antibodies in patients with visceral larva migrans. J.Infect Dis. 1977;135:633-40.

2. Beaver PC, Snyder CH, Carrera GM, Dent JH, Lafferty JW. Chronic eosinophilia due to visceral larva migrans. Report of three cases. Pediatrics. 1952;9:7-19.

3. Nichols RL. The etiology of visceral larva migrans. Diagnostic, morphology of infective second stage Toxocara larvae. J Parasitol. 1956;42:349-62. 
4. Shields JA. Ocular toxocariasis: a review. Surv Ophthalmol. 1984;28:361-81.

5. Bass JL, Mehta KA. Clinically inapparent toxocara infection in children. N Engl J Med. 1983;308:723-24.

6. Taylor MR, Keane CT, O'Conor P, Girdwood RW, Smith H. Clinical features of covert toxocariasis. Scand J Infect Dis. 1987;19: 693-6.

7. Bach-Rizzatti BC. Desenvolvimento de teste imunoenzimático, ELISA, para diagnóstico da toxocaríase humana [dissertação]. São Paulo (SP): Faculdade de Ciências Farmacêuticas da USP; 1984.

8. Bricks LF, Moyses MA, Kobinger MA. Hepatoesplenomegalia. In: Bresolin AM, Colli AS, Marcondes E, Moyses MA, Dias MH, editores. Pediatria em Consultório. São Paulo: Sarvier; 1985. p. 280-9

9. Naspitz CK, Solé D, Carneiro-Sampaio MM, Gonzalez CH. Níveis séricos de IgG, IgM e IgA de crianças brasileiras normais. J Pediatr (Rio J). 1982;62:121-6.

10. Thompson DE, Bundy DA, Cooper ES, Schantz PM. Epidemiological characteristics of Toxocara canis zoonotic infection of children in a Caribbean Community. Bull World Health Organ. 1986;64: 283-90.

11. Chieff PP. Contribuição ao Estudo da Síndrome de Larva Migrans Visceral por Toxocara em cinco Municípios do Estado de São Paulo, Brasil. Inquérito soroepidemiológico. São Paulo, 1984 [dissertação]. São Paulo (SP): Universidade de São Paulo; 1984.

12. Alonso JM, Bojanich MV, Chamorro M, Gorodnero JO. Toxocara seroprevalence in children from a subtropical city in Argentina. Rev Inst Med Trop S Paulo. 2000;42:235-7.

13. Moreira-Silva SF, Leão ME, Mendonça HF, Pereira FE. Prevalence of anti-Toxocara antibodies in a random sample of inpatients at a children's hospital in Vitória, Espírito Santo, Brazil. Rev Inst Med Trop S Paulo. 1998;40:259-61.

14. Alderete JM. Prevalência de infecção por Toxocara sp. em escolares na região do Butantã [dissertação]. São Paulo (SP): Universidade de São Paulo; 2001.

15. Baboolal S, Rawlins SC. Seroprevalence of toxocariasis in schoolchildren in Trinidad. Trans R Soc Trop Med Hyg. 2002; $96: 139-43$

16. Glickman LT, Magnaval JF, Domanski LM, Shofer FS, Lauria SS, Gottstein B, et al. Visceral larva migrans in French adults: a new disease syndrome? Am J Epidemiol. 1987;125:1019-34.

17. Worley G, Green JA, Frothingham TE, Sturner RA, Walls KW, Pakalnis VA, et al. Toxocara canis infection: clinical and epidemiological associations with seropositivity in kindergarten children. J Infect Dis. 1984;149:591-7.

18. Marmor M, Glickman L, Shofer F, Faich LA, Rosenberg C, Cornblatt B, et al. Toxocara canis infection of children: epidemiologic and neuropsychologic findings. Am J Public Health. $1987 ; 77: 554-9$.
19. Glickman LT, Schantz, Cypess RH. Epidemiological characteristics and clinical findings in patients with serologically proven toxocariasis. Trans R Soc Trop Med Hyg. 1979;73:254-8.

20. Montalvo AM, Espino AM, Escalante G, Finlay CM. Study of the seroprevalence of toxocariasis in infantile population in the city of Havana. Rev Cubana Med Trop. 1994;46(3):156-8.

21. Jacob CMA. Contribuição para o estudo da toxocaríase na infância: aspectos clínicos-laboratoriais de 40 casos [dissertação]. São Paulo (SP): Universidade de São Paulo; 1990.

22. Souza FA. Parâmetros clínicos e laboratoriais na evolução de 104 crianças portadoras de larva migrans visceral por Toxocaracanis [dissertação]. São Paulo (SP): Universidade Federal de São Paulo;1992.

23. Martinez FD, Wright AL, Taussig LM, Holberg $C$ J, Halonen $M$, Morgan WJ. Asthma and wheezing in the first six years of live. N Engl J Med. 1995;332:133-8.

24. Soares FJ, Rizzo MC, Solé D, Naspitz CK. Larva migrans visceral em bebê chiador. J Pediatr (Rio J). 1991;67:119-21.

25. Taylor MR, Keane CT, O'Connor P, Mulvihill E, Holland C. The expanded spectrum of toxocaral disease. Lancet. 1988;26:692-5.

26. Desowitz RS, Rudoy R, Barnwell JW. Antibodies to canine helminth parasites in asthmatic and nonasthmatic children. Int Arch Allergy Appl Immunol. 1981;65:361-6.

27. Buijs J, Borsboom G, van Gemund J], Hazebroek A, van Dongen $P A$, van Knapen $F$, et al. Toxocara seroprevalence in 5-year-old elementary schoolchildren: relation with allergic asthma. Am J Epidemiol. 1994;140:839-46.

28. Chan PW, Anuar KA, Fong M, Debruyne JA, Ibrahim J. Toxocara seroprevalence and childhood asthma among Malaysian children. Pediatr Intern. 2001;43;350-3.

29. Buijs J, Borsboom G, Reting M, Hilgersom WJ, Wieringen JC, Jansen $G$, et al. Relationship between allergic manifestations and toxocara seropositivity: a cross-sectional study among elementary school children. Eur Respir J. 1997;10:1467-75.

30. Minvielle MC, Niedfeld G, Ciarmela ML, De Falco A, Ghiani $H$, Basualdo JA. Asthma and covert toxocariasis. Medicina (B Aires). 1999;59:243-8.

Correspondence:

Silvana Delli Paoli de Figueiredo

Rua Arapá, 33/153, Bloco 1, Vila Mascote

CEP 04363-060 - São Paulo, SP

Brazil

Tel./Fax: +55 (11) 5679.6429

E-mail: kwcm@ig.com.br 